九州大学学術情報リポジトリ

Kyushu University Institutional Repository

\title{
Characterization of Solid Deposits formed in Geothermal Surface Facilities
}

Tusara, Loren

Department of Earth Resources Engineering, Graduate School of Engineering, Kyushu University

Itoi, Ryuichi

Deparbnent of Earth Resources Engineering, Faculty of Engineering, Kyushu University

https://doi.org/10.5109/1440969

出版情報: Evergreen. 1 (1)，pp.6-13，2014-03. Green Asia Education Center バージョン:

権利関係 : 


\title{
Characterization of Solid Deposits formed in Geothermal Surface Facilities
}

\author{
Loren Tusara $^{* 1}$, Ryuichi Itoi ${ }^{2}$ \\ ${ }^{1}$ Department of Earth Resources Engineering, Graduate School of Engineering, Kyushu University \\ ${ }^{2}$ Department of Earth Resources Engineering, Faculty of Engineering, Kyushu University \\ *Author to whom correspondence should be addressed, E-mail: 1tusara@kyudai.jp
}

(Received February 19, 2014; accepted March 4, 2014)

\begin{abstract}
Silica scaling has been one of the major problems in geothermal engineering. Scale prevention, monitoring and removal are necessary to counter excessive silica scaling in geothermal surface facilities and the reservoir. This study aims to characterize silica scales in terms of physical properties and chemical components. For this, the deposits are examined on the difference in density and porosity of silica scales formed in aging tank, canal and surface pipelines in the Otake and Tiwi geothermal fields, both of water-dominated system, as a measure to help in the mitigation process. Density has been found to not vary significantly across layers of the deposit for all samples. Average density of solid deposits from these two fields ranges from $2.15-2.20 \mathrm{~g} / \mathrm{cm}^{3}$. Apparent porosity, on the other hand, showed different trends in the result depending on the location of the sample in the surface facility. A homogenous porosity was observed for samples collected in surface pipelines. An increasing porosity was obtained for subaqueous solid deposits found near the aging tank. Similar trend in porosity was observed for samples obtained within the surface level of the aging tank. Iron and aluminum was detected in the sample but in very low composition compared to the amorphous silica that dominates the deposits.
\end{abstract}

\section{Introduction}

Water-dominated geothermal systems are prone to silica scaling issues. Silica remains in liquid-phase and thus becomes oversaturated after steam is extracted from the produced geothermal fluid. Excessive silica scaling in geothermal reservoir and surface facilities may cause breakdown of steam production. Mitigation of silica scaling involves either limiting of operating pressures; consequently of well output, or implementing silica inhibition methods. In the Wairakei geothermal field, the first geothermal power plant to have exploited the commercial significance and operation of wet geothermal resource ${ }^{1)}$, water is separated at a higher temperature to minimize the significant scaling of pipes and reservoir. It has a reservoir temperature of $260^{\circ} \mathrm{C}^{2)}$ and a separation temperature of $135^{\circ} \mathrm{C}^{3)}$. Separating, however, at high temperature does not exploit fully the potential of the geothermal field. In 2005, a binary system has been built to extract more energy from the spent fluid. Discharged geothermal fluids are either sent to the prawn farm in the adjacent area for direct-heat utilization or are sent back to the formation. The Otake geothermal field in northeastern Kyushu, Japan experienced excessive silica scaling in reinjection pipelines in its early stages. Yanagase et al. in a series of experiments have devised a method to lessen this silica scaling ${ }^{4)}$. In an ageing tank, the geothermal water was held for an hour before it was reinjected back to the formation. This retaining system through ponding allowed the dissolved silica to be partly converted to polymerized silica during that hold-up time. A satisfactory result has been observed in reducing the amount of deposits in the reinjection system. The Tiwi geothermal field in the Philippines also experiences silica scaling in the field. Aside from the regular mechanical clearing of pipes plugged with silica scale, they also make use of "cold brine" reinjection wherein they flash the separated water at atmospheric pressure before reinjecting back to the formation to deal with silica scaling. This "cold brine" reinjection reduces the amount of monomeric silica in the solution.

Laboratory and field experiments have been conducted to understand silica scaling mechanism. Rothbaum et al. investigated on the physical appearance of solid deposits through aging of geothermal waters ${ }^{5)}$. Effect of hydrodynamics was also studied to account for the particle size, fluid temperature, and velocity in the silica deposition process ${ }^{6), 7)}$. Chemical composition across the layers of the siliceous deposit was also investigated to know how the growth of silica proceeds in terms of the distribution of chemical components ${ }^{8)}$. A case study was also done to investigate the cause of the loss of reinjectivity of geothermal fields in Coso and Salton Sea where they found layers of silica scales with mineral precipitates in the soil structure ${ }^{9)}$.

Investigation of solid deposits has not only provided a better understanding of the deposition mechanism but it has also provided insights about the behavior of the 
geothermal reservoir. For cases of pipe and tank cleanups, information regarding the physical characteristic of the deposit might be helpful in coming up with a logistic to do the cleanup operation systematically. Matsuki et al. studied the removal of scales in geothermal pipes with high speed water jets, where tensile strength of the scale and the driving pressure of the water jet were observed to be roughly proportional to each other ${ }^{10)}$. Demir et al. have studied the type of scaling in hyper saline geothermal system in Tuzla, Turkey to aid in its scale prevention ${ }^{11)}$. Also, in the effort to estimate the amount of deposition in a pipe or in gravel beds, the inclusion of physical parameters such as density and porosity of the deposit is deemed to be necessary. These are parameters that briefly describe the nature of the solid deposit. Itoi et al. has included these parameters in their mathematical model of silica deposition ${ }^{12)}$.

This study provides a description of the physical characteristics of silica deposits, specifically the quantitative measures of density and porosity, from the Otake, and Tiwi geothermal fields. This also looks into the difference in porosity within layers of deposit in geothermal facilities.

\section{Method}

\subsection{Sampling of solid deposit}

Solid deposit samples were collected from surface facilities in the Otake geothermal field in the northeastern Kyushu, Japan and the Tiwi geothermal field in southeastern Luzon, Philippines. Both fields are of water-dominated system.

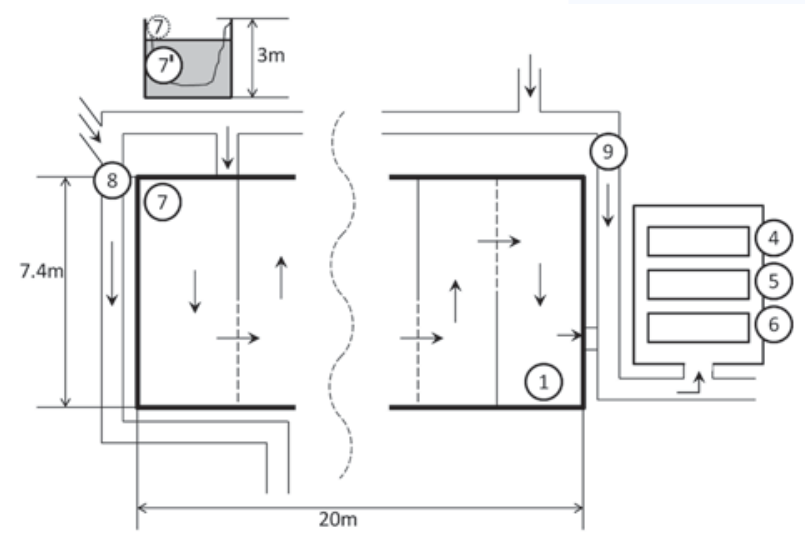

Fig. 1 Schematic diagram of sampling site in the Otake geothermal field

\subsubsection{Aging tank and canal}

Five solid samples from Otake were collected within and around the containment sump, which serves as an aging tank for the geothermal brine. The aging tank holds the geothermal water for about an hour allowing the monomer silica to polymerize before reinjecting the water to the formation through reinjection wells. Three samples were collected within the aging tank (OTK-1, OTK-7 and OTK-7'), and two along the canals (OTK-8 and OTK-9) as shown in Figure 1. The tank is 3m deep, $7.4 \mathrm{~m}$ wide and $20 \mathrm{~m}$ long. The flow of the geothermal water is shown in the figure. The collected samples are shown in Figure 2. The OTK-1 sample has a thickness of 9-14cm. OTK-7 sample has $10-12 \mathrm{~cm}$ thickness. OTK-7' sample has a thickness of $19 \mathrm{~cm}$. OTK- 8 and OTK-9 samples have thickness of $7-11 \mathrm{~cm}$.

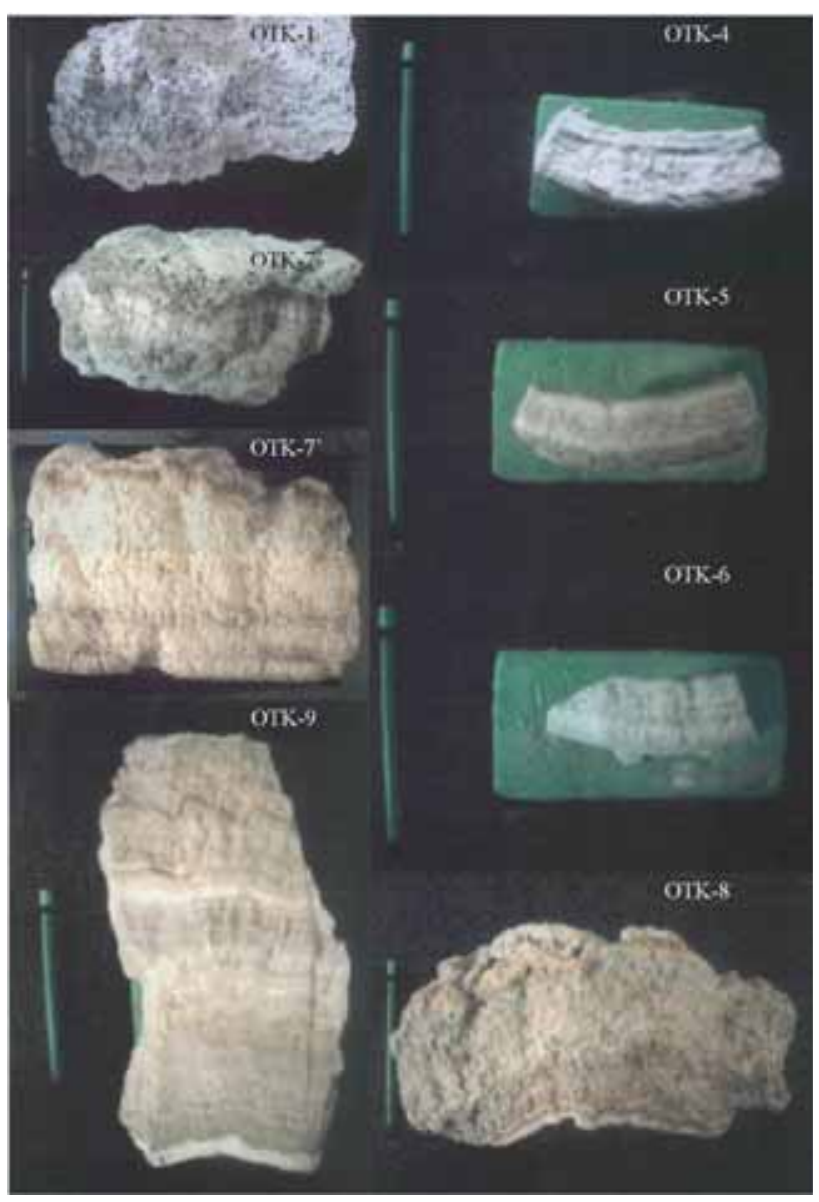

Fig. 2 Pictures of Otake samples.

\subsubsection{Surface pipeline}

OTK-4, OTK-5 and OTK-6 were all collected from the exit end of the pipes of the reinjection pumps in Otake as shown in Figure 1. They have thicknesses of $4 \mathrm{~cm}, 2 \mathrm{~cm}$ and $3 \mathrm{~cm}$, respectively.

Figure 3 shows the solid samples obtained from the Tiwi geothermal field. Solid deposits (TWI-1, TWI-2, TWI-3, TWI-4 and TWI-5) collected in Tiwi were obtained from five different decommissioned pipes that were used in the "cold brine" reinjection line. Each sample measured around a quarter of the pipe with 13-25 $\mathrm{cm}$ in width. The thickness of each sample depends on the amount of deposit in the pipe. 


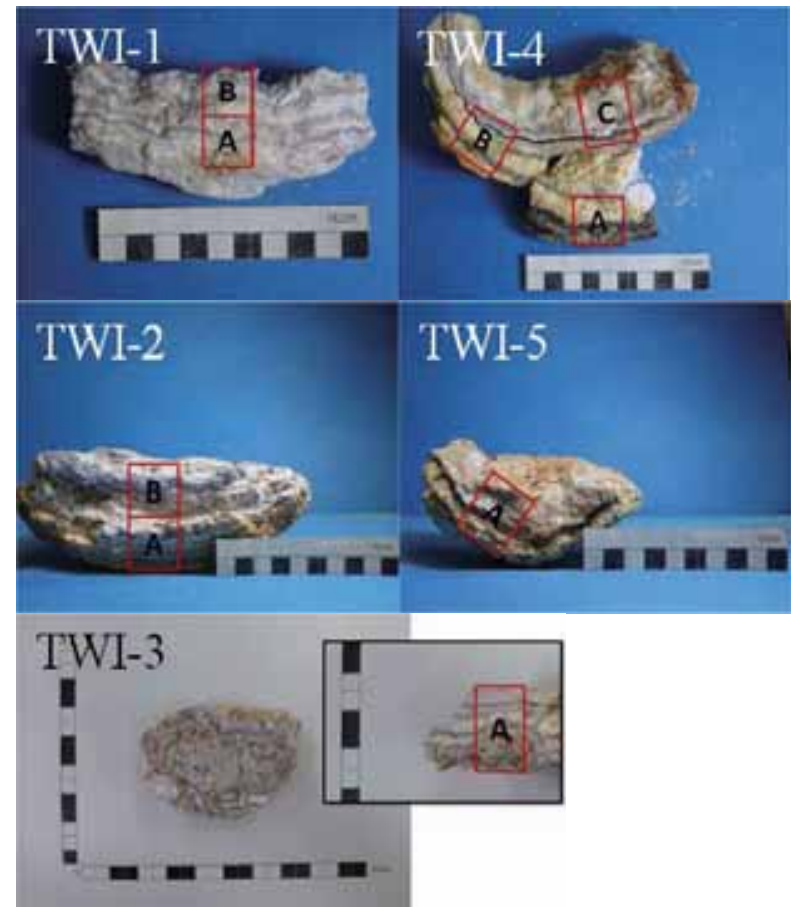

Fig. 3 Pictures of Tiwi samples.

\subsection{Sample preparation}

All solid deposit samples from Otake and TWI-1, TWI-2 and TWI-4 samples from Tiwi were divided into layers to represent chronological deposition on the surface. The number of layers depended on the thickness of each solid deposit. TWI-3 and TWI-5 samples were taken as is. There was not enough deposit to analyze for each layer. Adjacent cubes were obtained for each layer; one was analyzed for density and the other for apparent porosity. All samples were oven-dried for 24 hours at $105^{\circ} \mathrm{C}$ and were cooled down at room temperature in desiccant dehumidifier prior to measurement.

Solid samples for density measurement were pulverized using an agate mortar; while solid samples for apparent porosity measurement were coated with paraffin wax.

\subsection{Characterization methods}

\subsubsection{Density}

Density, $\rho\left(\mathrm{g} / \mathrm{cm}^{3}\right)$, of the solid deposit was measured using pycnometer method. It is calculated using Eq. (1),

$$
\rho=\frac{W_{2}-W_{1}}{\left[\left(W_{4}-W_{1}\right)-\left(W_{3}-W_{2}\right)\right]} \rho_{w}
$$

where $\mathrm{W}_{1}$ is the dry weight of the pycnometer with lid $(\mathrm{g}), \mathrm{W}_{2}$ is the dry weight of the sample in pycnometer with lid $(\mathrm{g}), \mathrm{W}_{3}$ is the weight of the sample after depressurizing and adding water up to the brim of the lid of the pycnometer $(\mathrm{g}), \mathrm{W}_{4}$ is the weight of the pycnometer with water up to the brim of the lid $(\mathrm{g})$, and $\rho_{\mathrm{w}}$ is the density of water at temperature $\mathrm{T}^{\circ} \mathrm{C}\left(\mathrm{g} / \mathrm{cm}^{3}\right)$.

\subsubsection{Apparent porosity}

The porosity of the deposit is the volume of pore spaces in a unit volume of sample. The apparent porosity was measured from the bulk density of the sample. The paraffin-coated sample was suspended in a string and was submerged in a water of known density. When the sample floated in the water, a cylindrical brass of known weight and volume was placed on the sample as added weight.

The bulk volume was measured from the amount of displaced water upon submersion. Porosity, $\phi(\%)$, was calculated as follows,

$$
\begin{aligned}
& \phi=\frac{V-V_{m}}{V} \times 100 \\
& V_{m}=\frac{W_{d}}{\rho_{s}} \\
& V=\frac{\left(W_{d}+W_{b}\right)-W_{w b}}{\rho_{w}}-V_{b}-V_{c}
\end{aligned}
$$

where $V_{m}$ is the volume of the sample $\left(\mathrm{cm}^{3}\right), \mathrm{V}$ is the bulk volume $\left(\mathrm{cm}^{3}\right), W_{d}$ is the dry weight of the sample $(\mathrm{g}), \rho_{\mathrm{s}}$ is the density of sample at temperature $\mathrm{T}^{\mathrm{o}} \mathrm{C}$ $\left(\mathrm{g} / \mathrm{cm}^{3}\right), \mathrm{W}_{\mathrm{b}}$ is the weight of the mass of the cylindrical brass $(\mathrm{g}), \mathrm{W}_{\mathrm{wb}}$ is the weight of the sample and the brass in water $(\mathrm{g}), \rho_{\mathrm{w}}$ is the density of water at temperature $\mathrm{T}^{\circ} \mathrm{C}\left(\mathrm{g} / \mathrm{cm}^{3}\right), \mathrm{V}_{\mathrm{b}}$ is the volume of the brass $\left(\mathrm{cm}^{3}\right)$, and $\mathrm{V}_{\mathrm{c}}$ is the volume of the paraffin coated on the sample $\left(\mathrm{cm}^{3}\right) . V_{\mathrm{b}}$ was calculated using the dimension, radius and height of the brass, and $V_{c}$ was calculated using the amount and density of paraffin wax $\left(\rho_{\mathrm{pw}}=0.9 \mathrm{~g} / \mathrm{cm}^{3}\right)$.

\subsubsection{XRD analysis}

X-ray diffraction (XRD) profile of the samples was obtained to examine the mineral composition of the deposit through its spectral information using a RigakuRINT-2100diffractometer.

\subsubsection{SEM-EDX analysis}

Scanning-electron microscopy (SEM) coupled with energy-dispersive x-ray spectroscopy (EDX) were used to identify the morphological structure of the deposit in depth and to determine the elements present in the sample (SS-550S, Shimadzu; EDAX). Due to the porous nature of the silica deposit, preparing a polished section of the samples for SEM-EDX analysis was difficult to make. Only a select polished sample from Tiwi was analyzed with SEM-EDX as representative sample.

\section{Results and discussion}

\subsection{Visual observation}

OTK-1, OTK-7 and OTK-7' were all collected from the wall of the aging tank. All samples were observed to 
have increasing pore sizes from the deposit near the wall to the surface of the deposit. Initial deposits in OTK-7 sample, which was located at the water level near the entrance of the aging tank, have smaller pore sizes compared to that in OTK-1, which was located near the exit of the aging tank. Layers of different morphological structure comprised both samples. OTK-1 deposit varied from soft to hard and brown to white from first layer to the exposed surface of the deposit, while OTK-7 deposit consisted of alternating porous and less porous layers. Both samples contained white, porous and fibrous-like striations oriented at the direction of the water flow. OTK-7' sample, a subaqueous deposit and the thickest among all samples, exhibited hard to soft layers of deposit where the topmost layer contained striations of brown and soft deposit. The OTK-8 and OTK-9 were collected in the open canal surrounding the aging tank near the entrance and in between the upper and lower tanks, respectively. These samples consisted of several layers each with different morphological structure. Layers of deposits varied in color appearance from the initial white deposit to alternating brown and gray deposits with white deposit finally comprising the topmost layer. Pore sizes seemed to decrease from bottom to top layer with large pores sparsely scattered in the sample. No change in pore size and color has been observed across layers for OTK-4, OTK-5 and OTK-6. It contained small pore sizes and particles and consisted of several $1 \mathrm{~mm}$ layers of deposit.

Solid deposit samples obtained from Tiwi have somehow similar texture with those obtained from Otake. All Tiwi samples were collected from decommissioned geothermal pipelines. TWI-1 has pronounced alternating layers of white and gray deposits. Initial deposits were harder than subsequent deposits. The topmost layer has a very soft deposit. TWI-2 has alternating layers of around $5 \mathrm{~mm}$ distinct white, brown and gray deposits. Subsequent $1 \mathrm{~cm}$-thick white deposit and gray deposit were also observed to have deposited. TWI-3 has similar physical appearance with TWI-1. The topmost layer contained large and soft particles that were sparsely distributed in the surface. The soft deposits can easily be pressed by finger. TWI-4 and TWI-5 has similar physical composition of the layers in the deposit. These samples contained a white-red-white deposit sandwiched between brownish white deposits. TWI-4 sample, however, consisted of an initial black and hard deposit near the pipe wall, which can hardly be pulverized with a mortar and pestle. All layers were observed to contain more pore spaces except for the black and red deposits that were seen in several samples.

Visual inspection of the formed solid deposit gives us an idea on the periods of deposition that occurred on the surface as manifested by the different layers in the deposit. Rothbaum et al. observed that the physical characteristics of the deposit changes with the variation in the fluid temperature, flow rate, $\mathrm{pH}$ and hold-up time. Hold-up time is defined as the duration of aging of the geothermal water before injection. Hard spiky scale deposits were observed for shorter hold-up time as compared to a soft scale deposit for streams that were hold-up for longer time. Little scaling was observed for $\mathrm{pH} 4$ and hard and much scaling for $\mathrm{pH} 8^{5 \text { ) }}$.

Color appearance of solid deposits also suggests the presence of other particles or chemical components in the deposit. Amorphous silica deposits usually appear as white or gray solid deposits. Solid samples obtained from Otake were mostly gray, especially those collected from the containment sump.

\subsection{XRD result}

XRD profiles of the Otake samples show a broad signal associated to amorphous silica as shown in Figure 4a. Results for Tiwi samples additionally include peaks corresponding to halite as shown in Figure $4 \mathrm{~b}$. Based on $\mathrm{XRD}$ result, Otake and Tiwi samples are rather homogenous in terms of mineral composition.

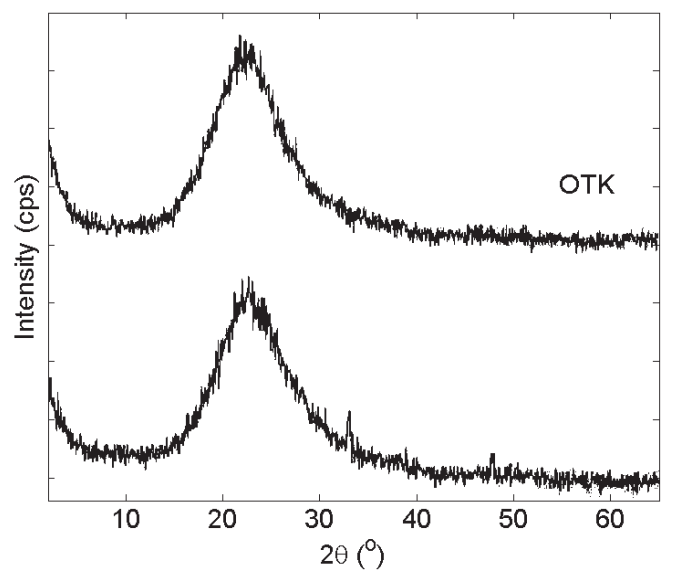

Fig. 4.a XRD data of OTK samples.

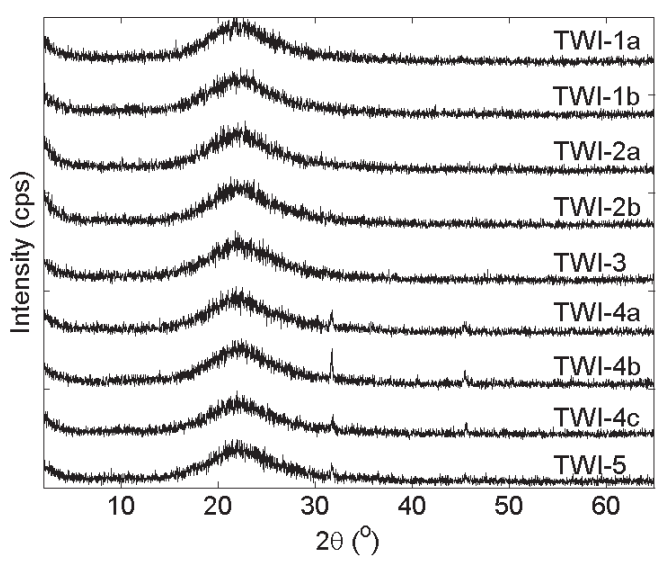

Fig. 4.b XRD data of TWI samples. Extra peaks seen in TWI-4 and TWI-5 samples correspond to halite, $\mathrm{NaCl}$.

\subsection{SEM-EDX result}

Results of SEM-EDX show the probable inclusion of 
$\mathrm{Fe}$ and $\mathrm{Al}$ in TWI-4 sample corresponding to the black and red deposit in the sample as shown in Figure 5a, respectively, however in low spectral signal compared to silica and the background signal. The iron deposit as shown in Figure 5b may have come from a corroding pipe upstream and the dissolved iron may have been transported downstream as suspended particle. The aluminum, on the other hand, as shown in Figure 5c may have come from an aluminum silicate, which formed in the solution and have precipitated as deposit.

The morphology of silica scales in the deposit was also analyzed in depth using SEM. Hand-picked locations in TWI-4 sample shows coalescence of spherical structures of amorphous silica deposits as shown in Figure 5d. In some pore spaces, tubular structures of $\mathrm{NaCl}$ were observed to precipitate as shown in Figure 5e. Chemistry of Tiwi geothermal brine showed a high content of $\mathrm{Na}$ and $\mathrm{Cl}$ ions of around $9000 \mathrm{ppm}$ and $16000 \mathrm{ppm}$, respectively ${ }^{13)}$. $\mathrm{NaCl}$ crystal may have formed from the remaining geothermal fluid in the sample when the sample was oven-dried during the sample preparation. The presence of $\mathrm{NaCl}$ is also observed in the XRD profile as peaks of halite.

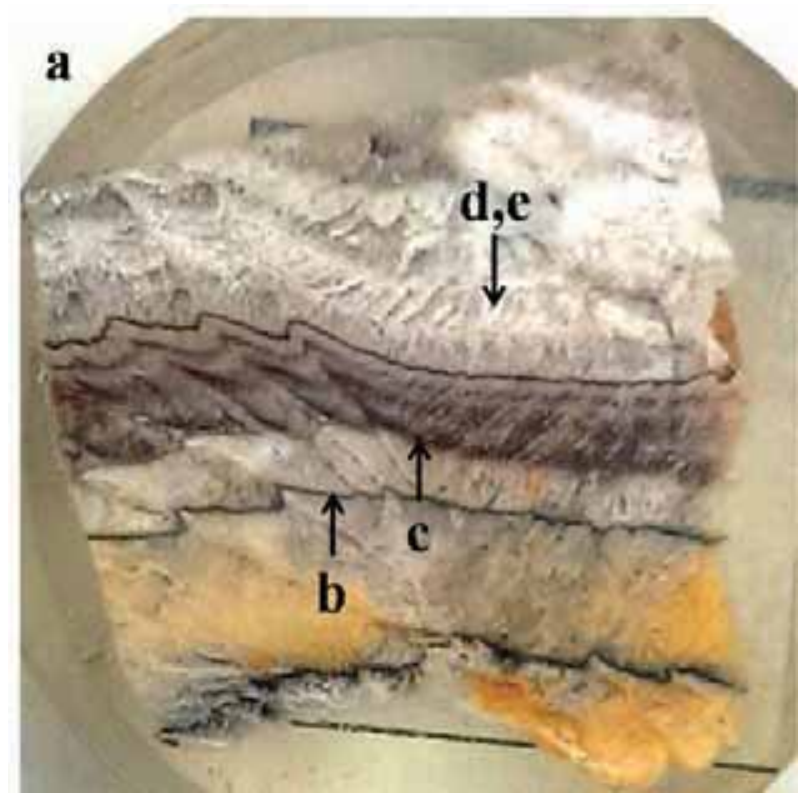

Fig. 5.a TWI-4 polished sample.

\subsection{Density}

Density of the solid deposit samples collected in the Otake and Tiwi geothermal fields fall on almost similar range that is lower than that of pure silica $\left(\rho=2.65 \mathrm{~g} / \mathrm{cm}^{3}\right)$. Table 1 summarizes the result of density measurement. The average of the measured density of the Otake samples obtained in the walls of the aging tank was 2.15 $\mathrm{g} / \mathrm{cm}^{3}$; while those that were collected in the pipe in the reinjection pump has an average measured density value of $2.18 \mathrm{~g} / \mathrm{cm}^{3}$. There is also no correlation seen in the distance of the deposit from the wall of the sump and pipe to the topmost layer of the deposits in terms of density values. It can be said that the Otake samples were homogenous in composition as also manifested in the result of XRD.

The Tiwi samples, on the other hand, have an average density value of $2.16 \mathrm{~g} / \mathrm{cm}^{3}$. The density of the solid deposit samples in Tiwi is similar to that of Otake samples. However, for Tiwi samples, a difference in density has been measured for the layers of samples of TWI-4. A decreasing density values from the pipe wall is observed in the result. This is associated with the difference in composition of solid deposit in the sample. This is the sample which has a hard black layer of deposit near the pipe wall as shown in Figure 3. Other layers also contained a hard reddish brown deposit as shown in Figure 5a.

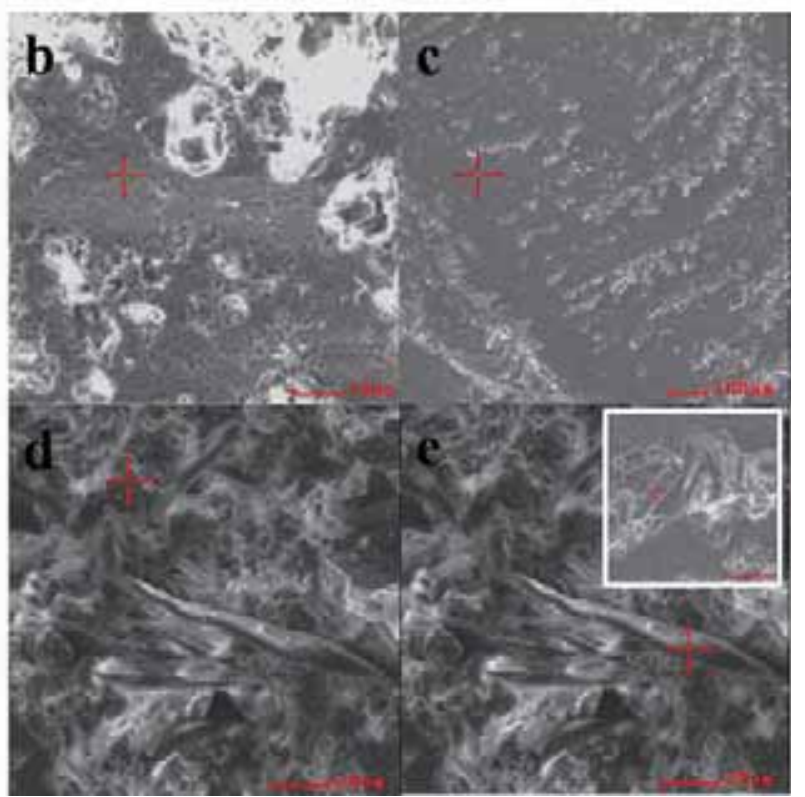

Fig. 5.b-e SEM-EDX result for points specified in Figure 4.a; b.)Si - 52.57 Wt $\%, \mathrm{O}-43.26 \mathrm{Wt} \%, \mathrm{Fe}-$ $3.24 \mathrm{Wt} \%, \mathrm{~S}-0.93 \mathrm{Wt} \%$, c.) $\mathrm{Si}-56.15 \mathrm{Wt} \%$, O $-43.27 \mathrm{Wt} \%, \mathrm{Al}-0.48 \mathrm{Wt} \%$, d.) Si -52.16 $\mathrm{Wt} \%, \mathrm{O}-47.84 \mathrm{Wt} \%$, e.) $\mathrm{Si}-22.49 \mathrm{Wt} \%, \mathrm{O}-$ $60.41 \mathrm{Wt} \%, \mathrm{Na}-8.55 \mathrm{Wt} \%, \mathrm{Cl}-8.54 \mathrm{Wt} \%$; the inlet with crosshair also corresponds to $\mathrm{NaCl}$ found at different location in the sample.

\subsection{Apparent porosity}

Different trends in the result of apparent porosity measurement for the samples were observed at different locations of samples. Result of porosity measurement is shown in Table 2.

\subsubsection{Near entrance of aging tank and canal}

A remarkable increase in porosity value has been observed for samples obtained in the sump and canal as shown in Figure 6. The OTK-7' solid deposit was collected in the aging tank near the entrance and OTK-8 was obtained in the open canal near the entrance of the aging tank. Both were located at the "start" of the reinjection system and were subaqueous deposits. This 
increase in porosity value may be associated to the ageing of silica gel which deposited on the surface. As monomeric silica deposits onto the surface and as other monomeric silica attaches to previously deposited silica, polymerization takes place while soft gel is formed in the process. As the silica gel ages, more water is drawn out from the deposit creating a stronger and more compact silica gel structure ${ }^{14)}$. This mechanism via dehydration may explain the increase in porosity value observed in the layers of OTK-7' and OTK-8 samples. Previously deposited silica experienced more dehydration in the process compared to the deposits found near the outermost layer; thereby having more condensed silica deposits in the first few layers. Less pore spaces were contained as more water is drawn out of the deposit. The flow through these sampling locations was rather slow due to its rather large and open space area; it was enough for the deposited silica gel to continue to form in the process without having washed off from the surface.

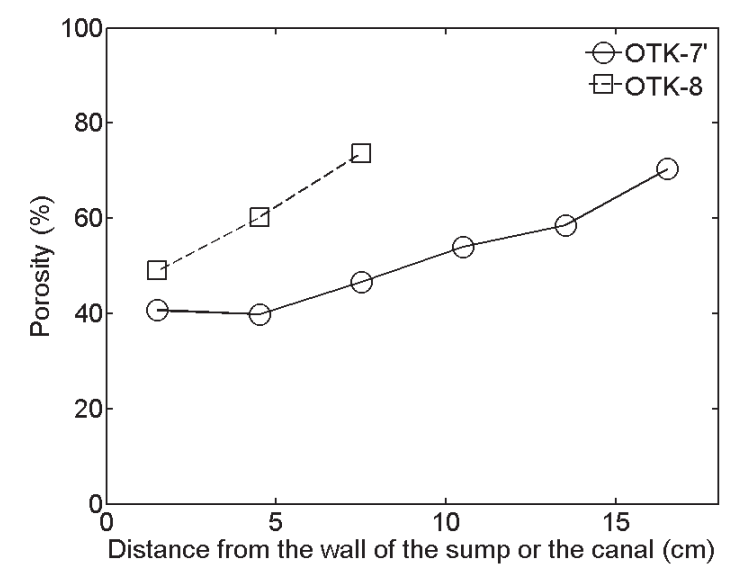

Fig. 6 Solid deposits located near the entrance of the aging tank.

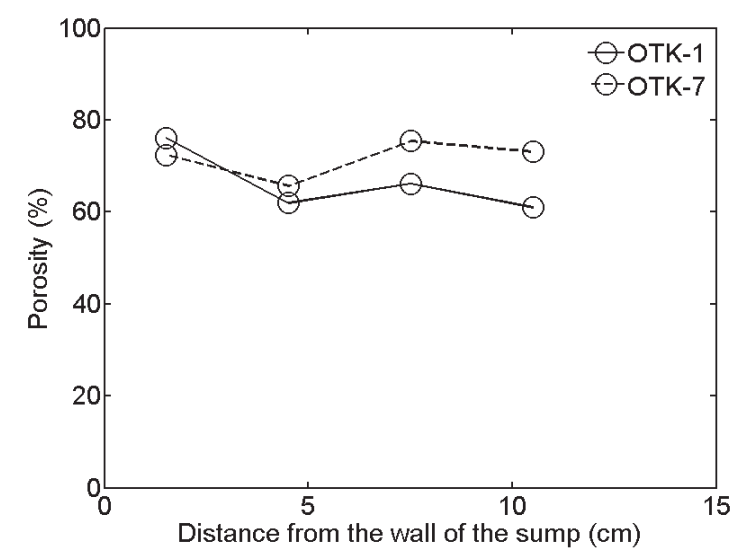

Fig. 7 Solid deposits collected in the aging tank at Otake.

\subsubsection{At surface level in aging tank}

Results obtained for the OTK-1 and OTK-7 samples are shown in Figure 7. Both exhibited the same trend in measured porosity values. Since both samples were collected from the same aging tank, this may explain the condition of the geothermal water in the aging tank during the deposition process. Having similar results as the deposit builds up on the surface suggests that both locations were experiencing the same condition during the duration of deposition. OTK-7', however was also collected from the aging tank, was situated at the middle part of the wall along the flow path of the aging tank where it may have always been submerged in geothermal water prior to shutdown of well production for maintenance operation; hence the difference in the porosity across its layers compared to that of OTK-1 and OTK-7.

\subsubsection{In surface pipeline}

Deposits that formed in pipelines behave differently from above. OTK-4, OTK-5 and OTK-6, which were obtained from reinjection pipes, have porosity values that were almost homogenous across layers as seen from Figure 8 .

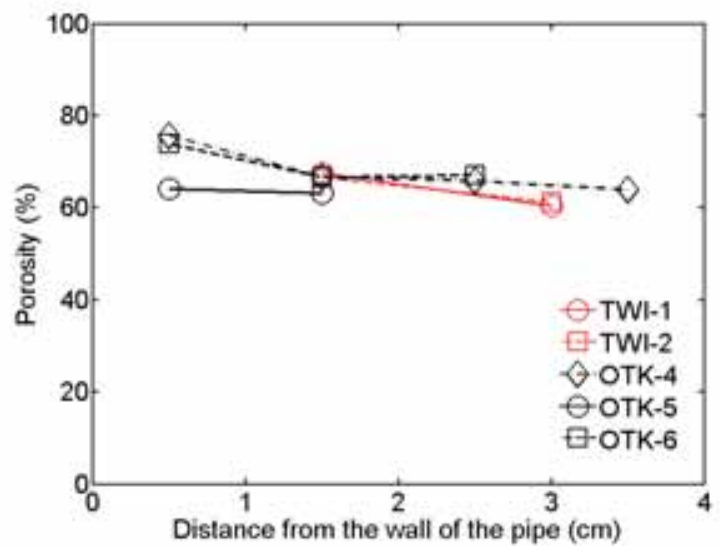

Fig. 8 Solid deposits obtained from decommissioned pipes.

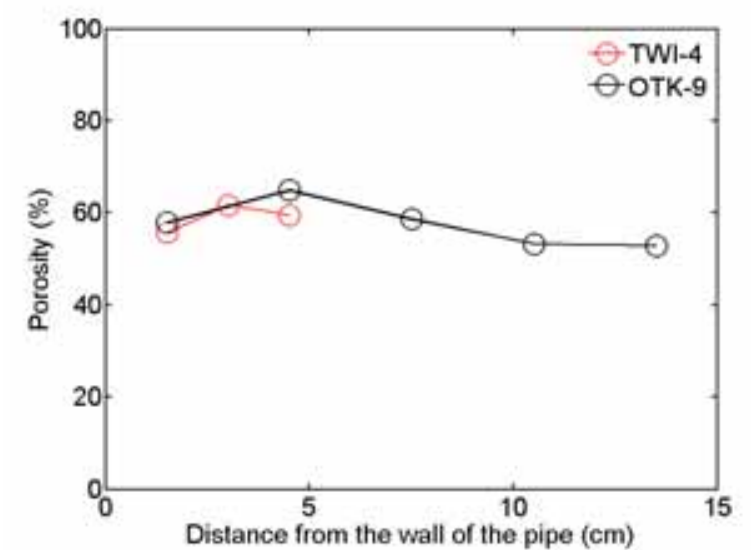

Fig. 9 Solid deposits which may have dense materials near the wall of the pipe.

Similar trend is observed for samples obtained in the pipelines of Tiwi (TWI-1 and TWI-2). Compared to the flow in the sump, flow in the pipelines is generally in 
turbulent condition. This may have prohibited the growth of silica gel to form on the surface as they were being washed away before it even matured. Colloidal particles in the solution may have grown in size and may have suspended in the downstream side due to particle inertia. While monomeric deposition may have taken place along the pipe walls, particle deposition may have also contributed in the deposits formed on the surface as suggested by the large porosity value observed in the deposits ${ }^{6}$.

Similarly for the TWI-4 and OTK-9 samples, which were obtained from the pipe and the canal, respectively, the deposits showed an almost homogeneous porosity value across its layers except for the initial layer which has lower porosity value compared to the subsequent deposited layer as shown in Figure 9. The initial layer of TWI-4 sample consists of dense hard black layer of deposit, which may have contributed to the decrease in apparent porosity value of this layer. Succeeding layers have roughly homogeneous porosity values. Similar result was obtained for the OTK-9 sample.

\section{Summary}

Solid deposits from geothermal fluid have almost similar density values for the samples obtained at surface facilities in the Otake and Tiwi fields. No variation in the density of the deposit was observed for different episodes of deposition in the samples except for a deposit in Tiwi which contained deposits other than that of the silica. Results of porosity measurement exhibited different trends in porosity values depending on the location of the solid deposit in the geothermal facility. Samples obtained from reinjection pipes have generally homogenous apparent porosity values across layers of deposit. Samples obtained near the entrance of the aging tank and canal and were subaqueous have an increasing porosity from the wall of the tank and canal to the exposed surface of the deposit. Samples obtained at the aging tank within the surface level at different location in the tank showed similar trend in porosity value for each layer of the deposit. Presence of iron and aluminum was also observed in one of the representative samples from Tiwi.

Knowledge on the physical properties of solid deposits found in the reinjection line provides aid in the maintenance operation in terms of silica scaling removal in the geothermal field. Estimation of silica scale production can be further improved considering the difference in the porosity of deposited silica scales and the average density of solid deposit in numerical models.

\section{Acknowledgements}

We wish to thank Kyushu Electric Power Co. Ltd. for allowing us to collect samples at Otake geothermal field. The same thank is extended to Philippines Geothermal Production Company, Inc., a Chevron company, for allowing us to conduct our data gathering at Tiwi geothermal field in Albay, Philippines and for providing assistance in the field. We also would like to thank Global COE program of Kyushu University for providing financial assistance for the fieldwork.

\section{References}

1) I. Thain, GHC Bulletin, 1 (1998).

2) A. Clotworthy, Proc. World Geothermal Congress, 2057, Kyushu- Tohoku (2000).

3) R. T. Harper and I. A. Thain, Proc. $14^{\text {th }}$ New Zealand Geothermal Workshop, 313, University of Auckland (1992).

4) T. Yanagase, Y. Suginohara and K. Yanagase, Geothermics, 2, 1621 (1970).

5) H. P. Rothbaum, B. H. Anderton, R.F. Harrison, A. G. Rohde and A. Slatter, Geothermics, 8, 1 (1979).

6) E. K. Mroczek and G. McDowell, Proc. $10^{\text {th }} \mathrm{New}$ Zealand Geothermal Workshop, 281, Auckland University (1998).

7) K. Brown and M. Dunstall, Proc. World Geothermal Congress, 3039, Kyushu-Tohoku (2000).

8) T. Yokoyama, Y. Sato, M. Nakai, K. Sunahara and R. Itoi, Geochem J., 33, 13 (1999).

9) K. S. McLin, J. N. Moore, J. Hulen, J. R. Bowman and B. Berard, Proc. 31st Workshop on Geothermal Reservoir Engineering, SGP-TR-179, Stanford University (2006).

10) K. Matsuki, K. Okumura and F. Sugimoto, J. GRSJ, 9, 255 (1987).

11) M. Demir, A. Baba, V. Atilla and M. Inanli, Geothermics, 50, 1 (2014).

12) R. Itoi, H. Maekawa, K. Tatsuta, M. Fukuda, K. Jinno, K. Hatanaka, S. Nozaki, T. Yokoyama and S. Shimizu, Trans. Geothermal Resources Council, 9-II, 337 (1985).

13) L. Tusara and R. Itoi, Inter. Symp. on Earth Science and Technology, ERDMT 19, Bandung (2012).

14) B. Mi and M. Elimelech, Desalination, 312, 75 (2013). 
Table 1 Average measured density for the representative solid deposit samples of each geothermal field.

\begin{tabular}{|c|c|c|c|}
\hline $\begin{array}{c}\text { Sample } \\
\text { ID }\end{array}$ & $\begin{array}{c}\text { Distance from } \\
\text { the wall of } \\
\text { sump or pipe } \\
(\mathrm{cm})\end{array}$ & $\begin{array}{l}\text { Density } \\
\left(\mathrm{g} / \mathrm{cm}^{3}\right)\end{array}$ & $\begin{array}{c}\text { Average } \\
\text { Density } \\
\left(\mathrm{g} / \mathrm{cm}^{3}\right)\end{array}$ \\
\hline \multirow{15}{*}{ OTK-7' } & 0.5 & 2.15 & \multirow{15}{*}{$2.15 \pm 0.03$} \\
\hline & 1.5 & 2.12 & \\
\hline & 2.5 & 2.16 & \\
\hline & 3.5 & 2.16 & \\
\hline & 4.5 & 2.22 & \\
\hline & 5.5 & 2.16 & \\
\hline & 6.5 & 2.17 & \\
\hline & 7.5 & 2.14 & \\
\hline & 8.5 & 2.16 & \\
\hline & 9.5 & 2.16 & \\
\hline & 10.5 & 2.14 & \\
\hline & 11.5 & 2.19 & \\
\hline & 12.5 & 2.13 & \\
\hline & 13.5 & 2.14 & \\
\hline & 14.5 & 2.12 & \\
\hline OTK-4* & & & $2.18 \pm 0.03$ \\
\hline \multirow{2}{*}{ TWI-1 } & 1.5 & 2.16 & \multirow{2}{*}{$2.14 \pm 0.03$} \\
\hline & 3.0 & 2.13 & \\
\hline \multirow{2}{*}{ TWI-2 } & 1.5 & 2.11 & \multirow{2}{*}{$2.13 \pm 0.03$} \\
\hline & 3.0 & 2.16 & \\
\hline TWI-3* & & & 2.14 \\
\hline \multirow{3}{*}{ TWI-4 } & 1.5 & 2.22 & \multirow{3}{*}{$2.18 \pm 0.04$} \\
\hline & 3.0 & 2.18 & \\
\hline & 4.5 & 2.14 & \\
\hline TWI-5* & & & 2.20 \\
\hline
\end{tabular}

* Stratigraphic analysis was not done on the solid deposit sample.
Table 2 Average measured porosity value for each layer of solid deposit.

\begin{tabular}{|c|c|c|}
\hline Sample ID & $\begin{array}{l}\text { Distance from } \\
\text { the wall of sump } \\
\text { or pipe }(\mathrm{cm})\end{array}$ & Porosity (\%) \\
\hline \multirow{4}{*}{ OTK-1 } & 1.5 & 76.2 \\
\hline & 4.5 & 62.0 \\
\hline & 7.5 & 66.2 \\
\hline & 10.5 & 61.0 \\
\hline \multirow{4}{*}{ OTK-4 } & 0.5 & 75.7 \\
\hline & 1.5 & 66.7 \\
\hline & 2.5 & 65.9 \\
\hline & 3.5 & 63.9 \\
\hline \multirow{2}{*}{ OTK-5 } & 0.5 & 64.1 \\
\hline & 1.5 & 63.1 \\
\hline \multirow{3}{*}{ OTK-6 } & 0.5 & 73.9 \\
\hline & 1.5 & 66.7 \\
\hline & 2.5 & 67.1 \\
\hline \multirow{4}{*}{ OTK-7 } & 1.5 & 72.4 \\
\hline & 4.5 & 65.7 \\
\hline & 7.5 & 75.4 \\
\hline & 10.5 & 73.1 \\
\hline \multirow{6}{*}{ OTK-7' } & 1.5 & 40.7 \\
\hline & 4.5 & 39.8 \\
\hline & 7.5 & 46.6 \\
\hline & 10.5 & 54.0 \\
\hline & 13.5 & 58.6 \\
\hline & 16.5 & 70.4 \\
\hline \multirow{3}{*}{ OTK-8 } & 1.5 & 49.0 \\
\hline & 4.5 & 60.2 \\
\hline & 7.5 & 73.7 \\
\hline \multirow{5}{*}{ OTK-9 } & 1.5 & 57.9 \\
\hline & 4.5 & 64.9 \\
\hline & 7.5 & 58.6 \\
\hline & 10.5 & 53.3 \\
\hline & 13.5 & 52.9 \\
\hline \multirow{2}{*}{ TWI-1 } & 1.5 & 67.6 \\
\hline & 3.0 & 60.4 \\
\hline \multirow{2}{*}{ TWI-2 } & 1.5 & 66.5 \\
\hline & 3.0 & 61.3 \\
\hline TWI-3 & 1.5 & 65.7 \\
\hline \multirow{3}{*}{ TWI-4 } & 1.5 & 55.7 \\
\hline & 3.0 & 61.7 \\
\hline & 4.5 & 59.6 \\
\hline TWI-5 & 1.5 & 66.8 \\
\hline
\end{tabular}

